Article

\title{
Strain Rate Dependence of Hardness for PE and SME TiNi Alloys
}

\author{
Lingyan Shen, Mengmeng Hui and Yonggui Liu * \\ School of Civil Engineering, Henan Polytechnic University, Jiaozuo 454000, China; lyshen@hpu.edu.cn (L.S.); \\ 211808010009@home.hpu.edu.cn (M.H.) \\ * Correspondence: liuyongg@hpu.edu.cn; Tel.: +86-391-3987649
}

Received: 18 July 2020; Accepted: 18 August 2020; Published: 27 August 2020

check for updates

\begin{abstract}
In this paper, the strain rate dependence of hardening behavior of polycrystalline pseudoelastic (PE) and shape memory effect (SME) TiNi alloy under impact loading was investigated by experiments. Measurements of stress-strain curves, hardening modulus, hysteresis loop area, and temperature variation are synchronized using in situ infrared detector system at the strain rate range from 300/s to 2000/s. It is shown that with the strain rate increasing, for PE specimens, strain rate hardening is observed, while SME specimens perform a strong nonlinear strain hardening. The results of synchronous temperature measurement show that in stress-temperature space, for PE samples, the dynamic transformation path is strain rate independent, but for the SME samples, the opposite is true. Thermal-mechanical coupling does not seem to explain this difference, and hardening from microstructure variation should be considered for such difference.
\end{abstract}

Keywords: shape memory materials; phase transformation; hardening; strain rate effect; temperature evolution

\section{Introduction}

Due to the first-order martensitic phase transition, TiNi shape memory alloy (SMA) is well known for two excellent properties: pseudoelasticity (PE) and shape memory effect (SME), which have been exploited in a variety of fields, such as smart actuators, damping device, micro-electro-mechanical-systems, biomedical applications [1], and so on.One of the key concerns in such applications is itsrate sensitivity of the material's performance. In recent decades, great efforts have been made to study the rate dependent behavior of TiNi alloy, including (1) rate-dependent transformation fronts in different structures (wire, plates, and tubes) [2-6]; (2) rate-dependent stress hysteresis and hardness [7-10]; (3) heat transfer analysis and simulations on the front motion [11,12]. The results show that the mechanism of the strain rate effect lies in the temperature dependence of transformation stress. However, most studies were focused on tensile strip and wire samples under quasi-static state, and mostly for PE TiNi alloy.

As for dynamic conditions, there are some works which have studied the behavior of SMAs at very high strain rates, up to $10^{3} / \mathrm{s}$ [13]. Experimental techniques, such as the split Hopkinson pressure bar technique (SHPB) have been used to achieve these higher strain rates. However, their research only focuses on the strain rate dependence of transformation stress and dissipation energy. In the intermediate range, Chen et al. [14] studied the dynamic compressive PE behavior of a TiNi shape memory alloy at strain rates of 81-750/s. It was shown that the compressive stress-strain cures show an open hysteresis loops, what is more, dynamic strain lags behind stress during loading and unloading at higher strain rates. On the order of $1 \sim 10^{2} / \mathrm{s}$, Zurbitu et al. [15] studied the tensile behavior of PE TiNi alloys. However, the above dynamic experimental research work is performed under the framework of pure mechanics without the thermo-mechanics coupling effect. So that, the aim of this work is to 
carry out the dynamic hardening characterization of PE and SME TiNi SMA at impact strain rates over the range $10^{2}-10^{3} / \mathrm{s}$ by a modified SHPB instrumented.

\section{Material and Methodology}

Polycrystalline available Ni 50.9 at.\% Ti rods(Nitinol Devices \& Components Fremont, Inc., Fremont, CA, USA) were used in the present study. The as-received TiNi rods were annealed at $800{ }^{\circ} \mathrm{C}$ for $30 \mathrm{~min}$ to obtain a uniform coarse-grained microstructure with a mean grain size of $30 \pm 5 \mu \mathrm{m}$. Cylindrical specimens with a diameter of $8 \mathrm{~mm}$ and $6 \mathrm{~mm}$ length were wire-cut and annealed in different conditions to achieve PE and SME stage specimens at room temperature $\left(24.4^{\circ} \mathrm{C}\right)$, respectively. The transformation temperature was determined from the differential scanning calorimetry (DSC) peaks using the slope line extension method, as shown in Figure 1. In particular, for PE specimens, the forward martensitic transformation starts at $-20.4{ }^{\circ} \mathrm{C}\left(\mathrm{M}_{\mathrm{s}}\right)$ and finishes at about $-51.5{ }^{\circ} \mathrm{C}\left(\mathrm{M}_{\mathrm{f}}\right)$ during cooling, while upon heating, the reverse transformation starts at about $-31.6^{\circ} \mathrm{C}$ (As) and finishes at about $-0.3^{\circ} \mathrm{C}\left(\mathrm{A}_{\mathrm{f}}\right)$ and for SME specimens, the characteristic temperatures, $\mathrm{M}_{\mathrm{s}}, \mathrm{M}_{\mathrm{f}}$, Asand $\mathrm{A}_{\mathrm{f}}$ are $11.4^{\circ} \mathrm{C}, 7.0^{\circ} \mathrm{C}, 47^{\circ} \mathrm{C}$ and $53^{\circ} \mathrm{C}$, respectively. It should be noted that before testing, the SME specimen was heated in boiling water for $15 \mathrm{~min}$, then it is taken out and cooled naturally to the room temperature. The room temperature is higher than Ms point of SME TiNi, so the specimen will be still in austenite phase.

Dynamic tests were completed in the laboratory of impact dynamics in university of science and technology of China. The split Hopkinson pressure bar device (SHPB) apparatus was used to provide impact loading, which has been articulated and now widely used for dynamic compression, as shown in Figure 2a. The working principles and technical details of SHPB can be found elsewhere [16]. In situ temperature can be measured by an infrared detector system (IR, red line in Figure 2), including an optical system with 2:1 magnification and a single element IR detector. The detector is made of $\mathrm{HgCdTe}$ (J15D12-M204-S01M-60, Judson Co., Decatur, AL, USA) that responds to radiation in the 8 to $14 \mu \mathrm{m}$ wavelength range, corresponding to temperature from 300 to $400 \mathrm{~K}$, which is adequate for measuring surface temperature of the specimen during impact loading. The response time for the detector system is less than $1 \mu \mathrm{s}$, fast enough for SHPB tests. Calibration of the IR system is of vital importance to the reliability and accuracy of temperature measurement. A relationship between temperature and voltage needs to be established before the actual test. More details of each of the components of the system and calibration process are given in $[17,18]$. A typical strain and temperature and wave signal for PE and SME is shown in Figure 2b,c, respectively. Based on the measured waveform, the dynamic stress-strain curve of the material can be obtained by the three wave method [16], and the corresponding temperature can be calculated through the calibration curve.

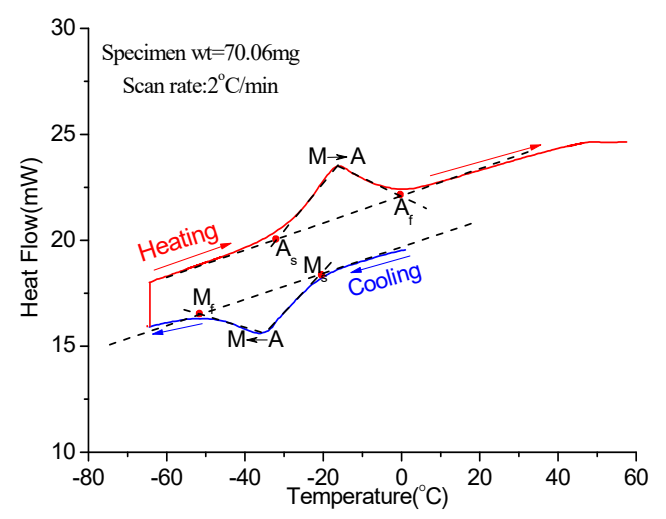

(a) For PE

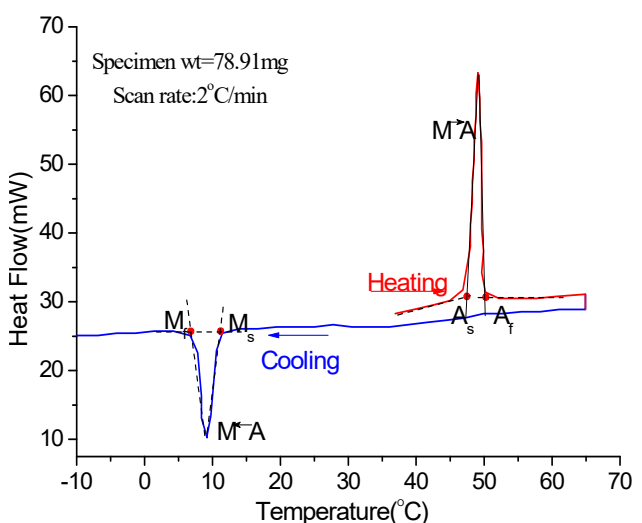

(b) For SME

Figure 1. Differential scanning calorimetry (DSC) cure of TiNi alloy specimens. (a) For PE; (b) For SME. 


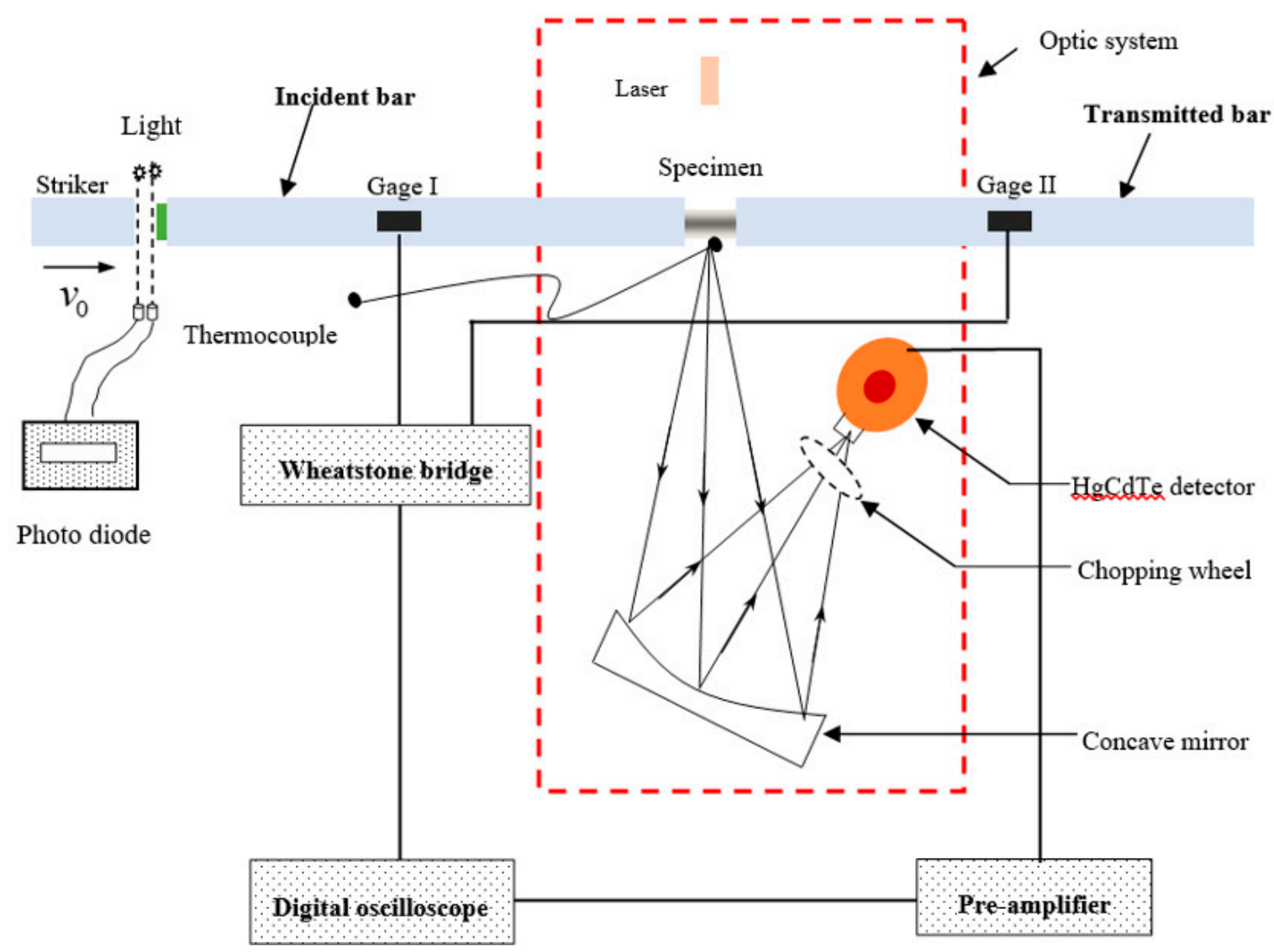

(a) Schematic illustration of the experimental setup

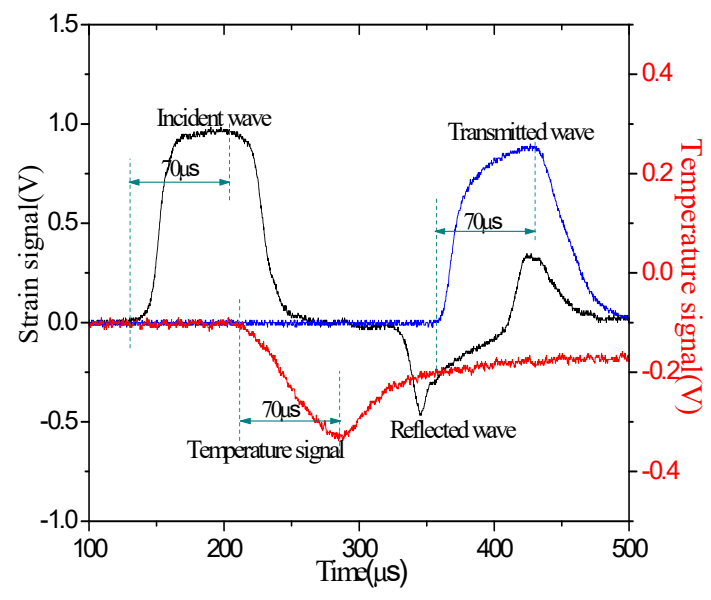

(b) Typical signal for PE

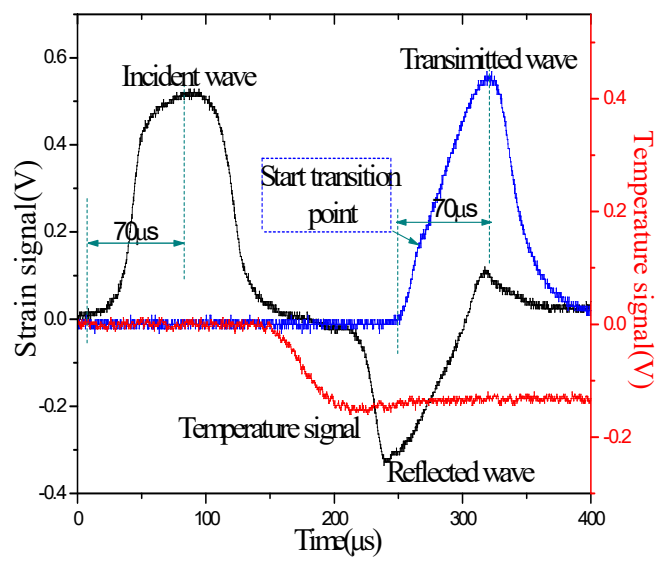

(c) Typical signal for SME

Figure 2. Experimental setup and typical wave profiles. (a) Schematic illustration of the experimental setup; (b) Typical signal for PE; (c) Typical signal for SME.

In SHPB experiments, dynamic stress equilibrium is a fundamental requirement for valid data processing, because equilibrium is one of the basic assumptions upon which SHPB theory is built [16]. A homogeneously-deforming specimen under a dynamic equilibrium state of stress makes the volume-average of the specimen's behavior representative of the point-wise material properties. In our experiments, we checked stress equilibrium by comparing the transmitted stress signal with the difference between the incident and reflected stress signals. Figure 3 shows the results of such an analysis on the stress pulses of Figure $2 b$,c. There are two nearly overlapping curves, indicating that dynamic equilibrium stress state in the specimen has been achieved. 


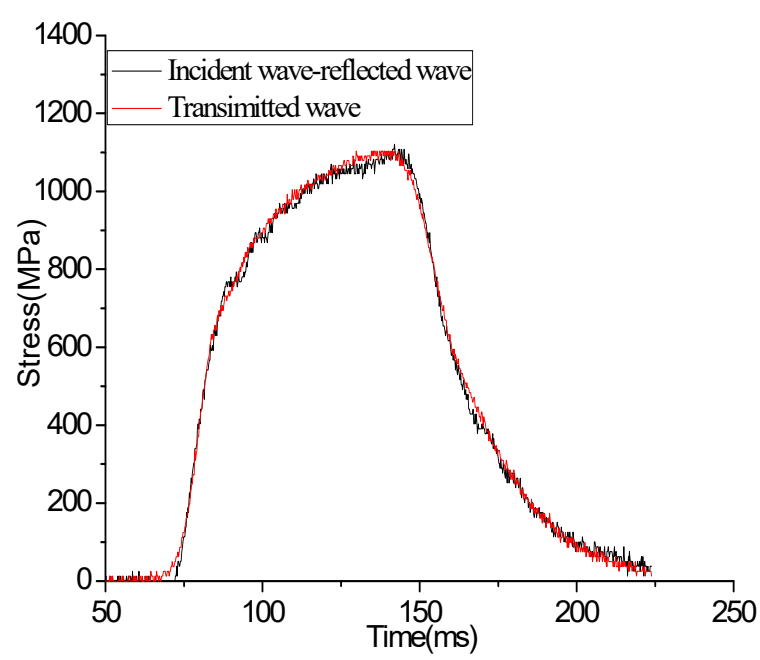

(a) For PE

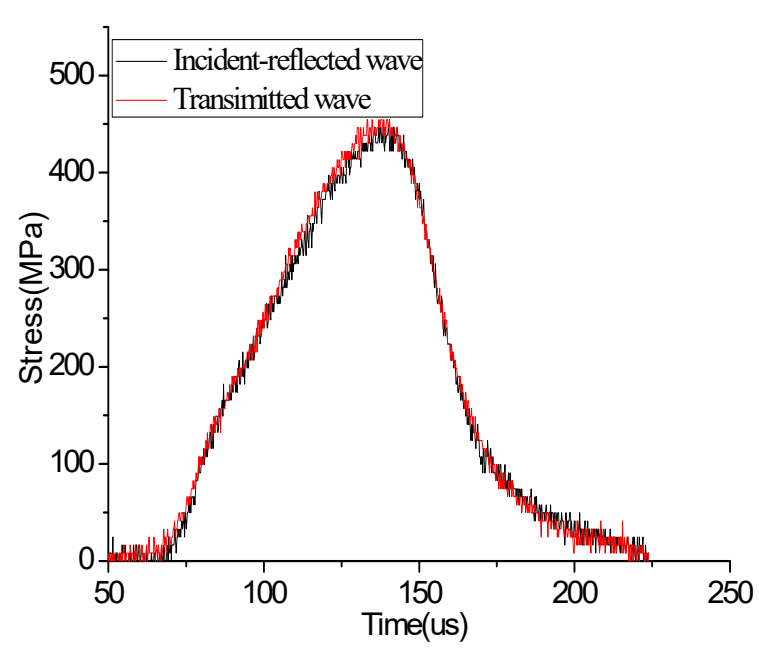

(b) For SME

Figure 3. Analysis of dynamic stress equilibrium. (a) For PE; (b) For SME.

\section{Results and Discussion}

The dynamic stress-strain cures under different strain rates are shown in Figure 4a,c. It is seen that with the increase of strain rate, for PE samples, the slopes of forward phase transformation increases gradually, showing a remarkable strain rate hardening characteristic. In contrast, for SME samples (see Figure 4c), strong nonlinear strain hardening feature is observed, exhibiting more amazing memory behavior. At strain rate of 2000/s, a turning point (D in Figure 4c) occurs during unloading, which reflects the change of unloading mode. What is more, there exists residual strain both for PE and SME, depending on the strain rate. Such residual deformation can be wholly recovered when the recycled samples are heated again, suggesting that, in the process of dynamic transformation, there is no plastic deformation or crack initiation/or propagation.

Obtaining the macroscopic hardening modulus $E_{\mathrm{p}}$, i.e., slope of the loading mixed phase and hysteresis loop areas $W_{\mathrm{d}}$ (dissipated energy) from the stress-strain curves, the relationship between $E_{\mathrm{p}}$ and the stain rate $\dot{\varepsilon}$ and that between $W_{\mathrm{d}}$ and $\dot{\varepsilon}$ are shown in Figure $4 \mathrm{~b}$,d. Two important features are observed as following. First, in the case of $\mathrm{PE}, E_{\mathrm{p}}$ varies monotonically with an increase in strain rate, ranging from about 3.5 GPa at the strain rate of 300/s to 15.2 GPa for strain rate of 2000/s, which is in consistent with previous findings [17]. In the case of SME, hardness (slopes of secant line linking maximum stress point and initial stress point) increased approximately linearly with the strain rate increasing. Second, $W_{\mathrm{d}}$ varies monotonically with strain rate, which plays an important role for fatigue of SMA, which is totally different from results in [9]. In their results, $W_{\mathrm{d}}$ change non-monotonically, with the strain rate ranging from $0.0001 / \mathrm{s}$ to $1 / \mathrm{s}$.

The corresponding measured temperature are demonstrated in Figure 5. It is seen that, similar to previous studies [11], there is detectable temperature rise at the initial loading, and an apparent temperature rise is observed after the initial critical stress. Under a given strain rate, the difference of temperature evolution between PE and SME is mainly reflected in unloading process: for PE, temperature decreased because of unloading endothermic, but, for SME, temperature keeps the maximum constant at low strain rates (300/s 1300/s) and decreased at high strain rate (2000/s). This is because, when the strain rate is up to $2000 / \mathrm{s}$, the maximum temperature increased to $54.2^{\circ} \mathrm{C}$, higher than the characteristic temperature $A_{s}\left(47^{\circ} \mathrm{C}\right)$, which changes the unloading path from elastic to partial inverse phase transition (Point D in Figure 4c). In addition, it can be seen that the maximum temperature rise increases monotonously, with the strain rate increasing (see Figure 5c,d). 


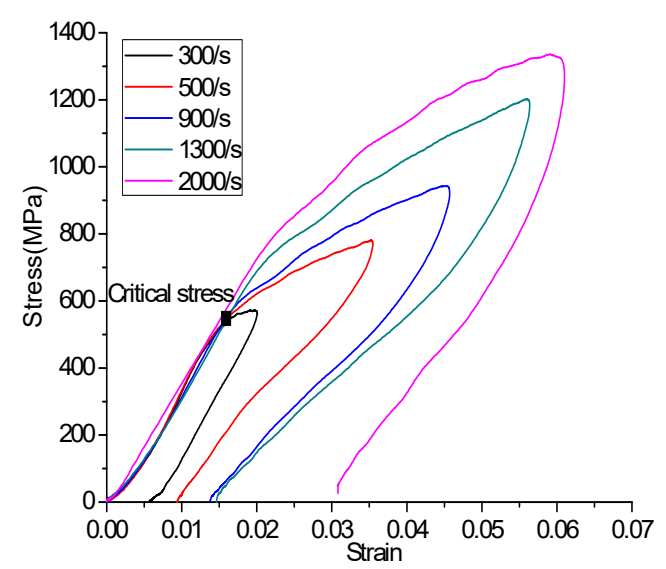

(a) Stress-strain curves for pseudoelastic (PE)

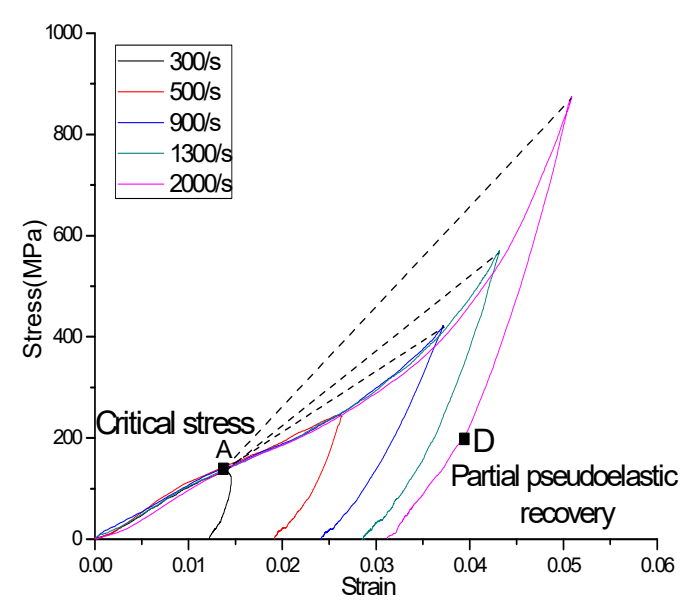

(c) Stress-strain curves for shape memory effect (SME)

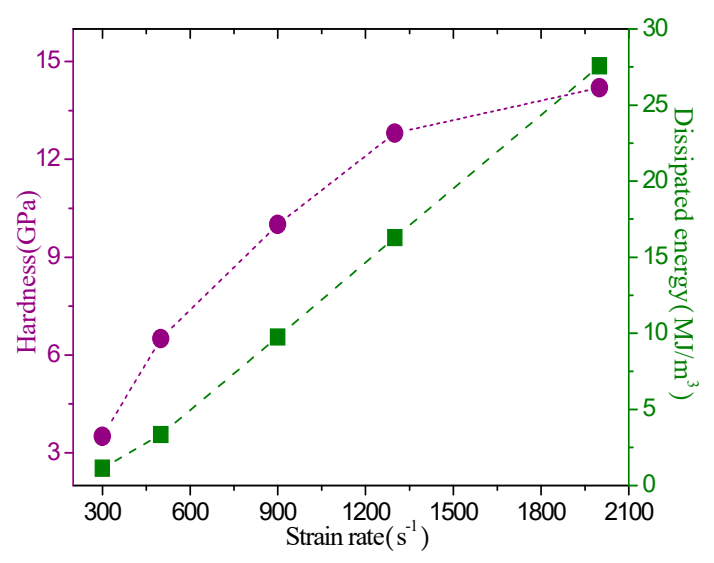

(b) Slopes and dissipated energy for PE

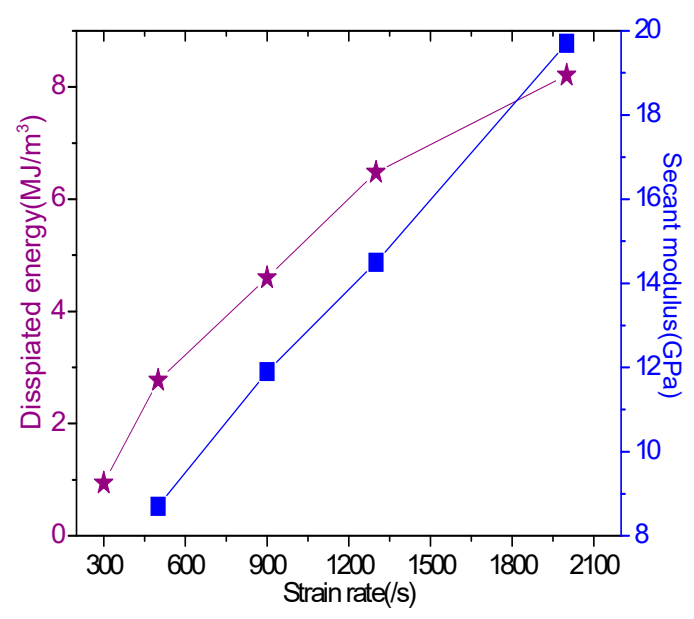

(d) Slopes and dissipated energy for SME

Figure 4. Dynamic response for SME and PE under different strain rates. (a) Stress-strain curves for pseudoelastic (PE); (b) Slopes and dissipated energy for PE; (c) Stress-strain curves for shape memory effect (SME); (d) Slopes and dissipated energy for SME.

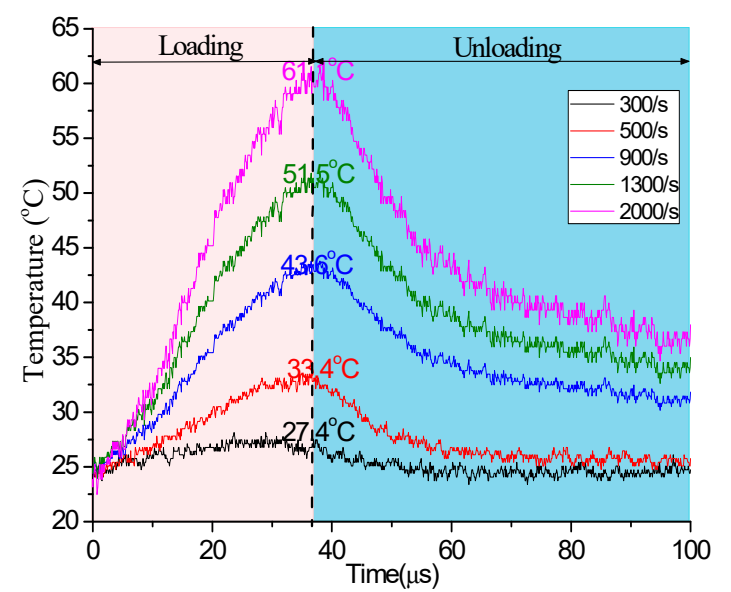

(a) Temperature evolution for PE

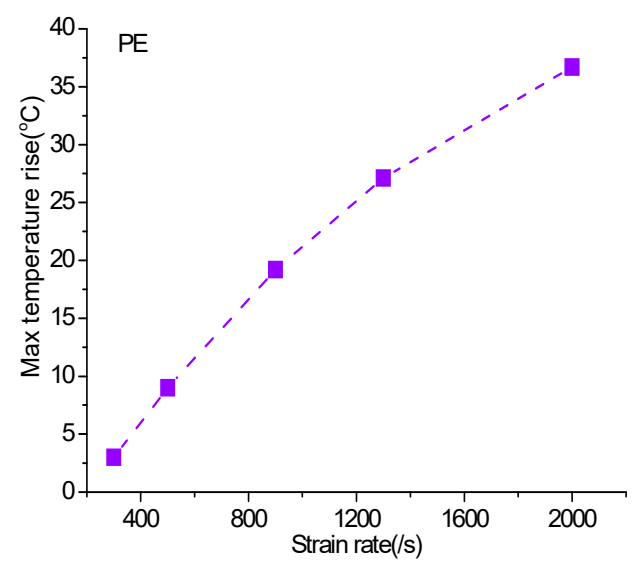

(b) Temperature rise vs. strain rate for PE

Figure 5. Cont. 


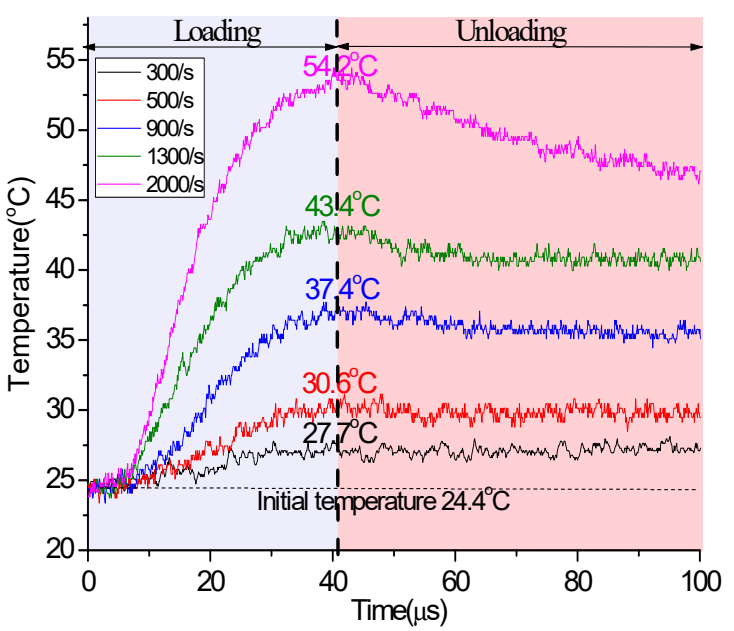

(c) Temperature evolution for SME

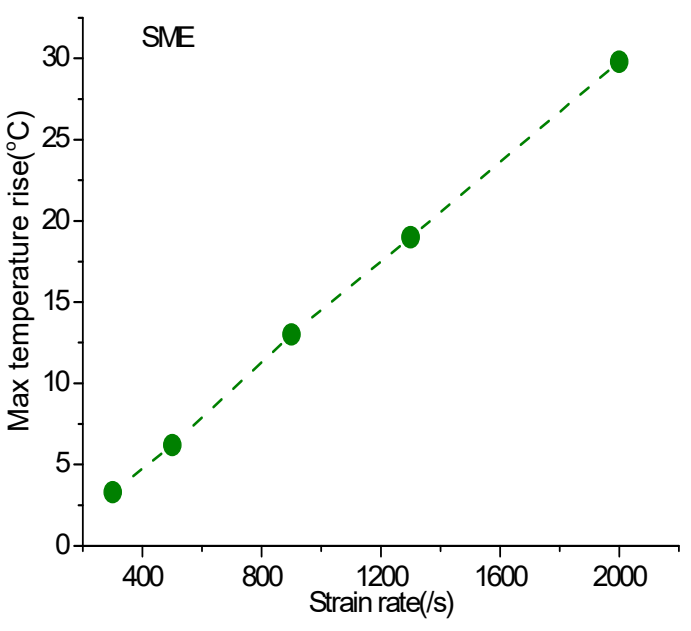

(d) Temperature rise vs. strain rate for SME

Figure 5. Temperature evolution under different strain rates. (a) Temperature evolution for PE; (b) Temperature rise vs. strain rate for PE; (c) Temperature evolution for SME; (d) Temperature rise vs. strain rate for SME.

In stress-temperature space, as shown in Figure 6, it can be seen that for PE, phase transition paths are almost parallel (about $15.4 \mathrm{MPa} / \mathrm{K}$ ), suggesting that the strain rate does not affect transition path. For SME, the transformation path line shifts and significant strain rate effect can be observed (see Figure 6b). Moreover, temperature evolution is synchronized with stress variation. As such, it is believed that the dynamic transformation deformation is uniform.On the contrary, from experiments of adiabatic shear [19], phase transformation band propagation [20-22], the delay of temperature rises with respect to stress was observed, which is due to the non-uniform deformation. In addition, the transition of unloading path (point D in Figure 6b) can be clearly seen at strain rate of 2000/s, which is consistent with the result in Figure 4c. The observed fact that temperature evolution happens quite consistent with transformation stress suggests that it should be the cause of hardening. As the transformation proceeds, the temperature increases, and higher stress is needed to drive the continuous transformation, since the intrinsic temperature dependence of the transformation stress, showing hardening behavior. However, why are they so different in case of PE and SME, respectively? Thermal-mechanical coupling does not seem to explain this difference. As such, we believe that hardening from microstructure variation should be equally true for such hardening.

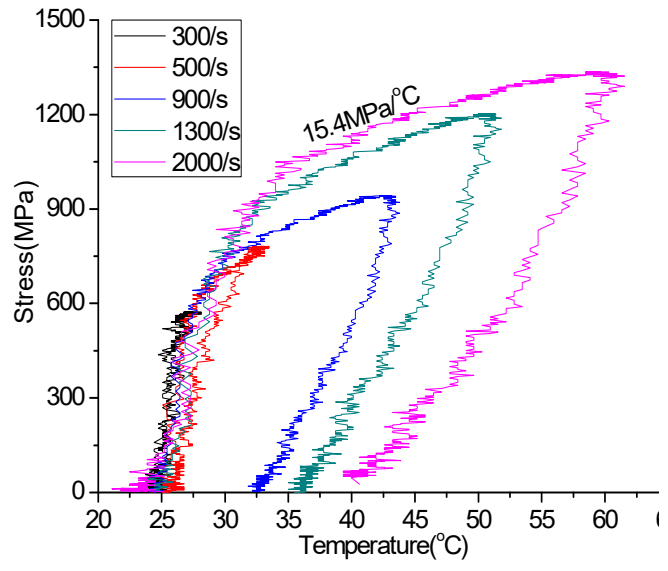

(a) For PE

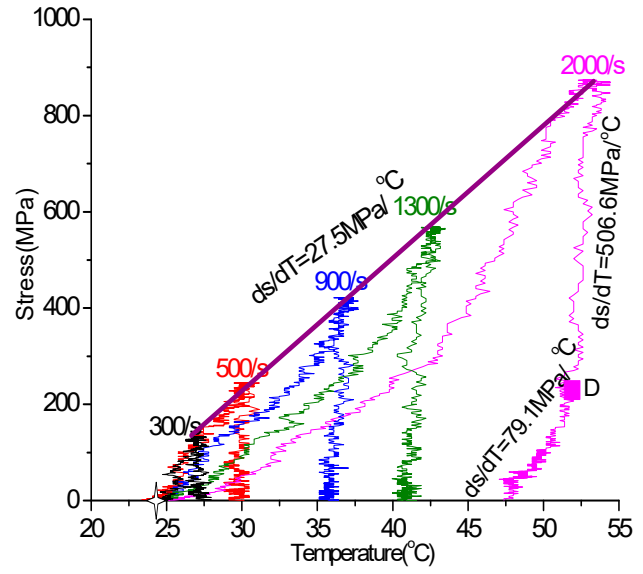

(b) For SME

Figure 6. Dynamicphase transformation paths for PE and SME TiNi alloys. (a) For PE; (b) For SME. 


\section{Conclusions}

The dynamic hardening behavior of the PE and SME TiNi alloy subjected to impact loading is studied experimentally in the present paper. According to the dynamic stress-strain curves, the PE specimen shows obvious strain rate hardening features, however, in the stress temperature space, the effect of strain rate on the real-time dynamic path of phase transformation is not significant. The mechanism lies in the temperature dependence of phase transformation stress, that is, the temperature rise caused by phase transformation deformation makes the further phase transformation need higher stress to drive, which shows a significant strain rate hardening feature on the macro level. In contrast, the SME specimen displays strong nonlinear strain hardening characteristics without strain rate effect, but the dynamic phase transition path shows remarkable strain rate dependent. It seems that the thermal mechanical coupling mechanism cannot explain such strain hardening characteristics and the strain rate effect of the transformation path for SME TiNi alloy. Moreover, it is impossible to make a reasonable analysis of the differences between PE and SME. Further efforts should be taken to theoretically reveal the intrinsic mechanism of the hardness difference between PE and SME TiNi alloy.

Author Contributions: Formal analysis, L.S.; investigation, M.H.; methodology, Y.L.; writing-original draft, L.S.; writing-review \& editing, Y.L. All authors have read and agreed to the published version of the manuscript.

Funding: This research was funded by National Natural Science Foundation of China (Project No.: 11702086) and Natural Science Foundation of Henan Province (grant number: NSFRF 180422).

Conflicts of Interest: The authors declare no conflict of interest.

\section{References}

1. Otsuka, K.; Wayman, C.M. Shape Memory Materials; Cambridge UniversityPress: Cambridge, UK, 1999.

2. Shaw, J.A.; Kyriakides, S. On the nucleation and propagation of phase transformation fronts in a NiTi alloy. Acta Mater. 1997, 45, 683-700. [CrossRef]

3. Bruno, O.P.; Leo, P.H.; Reitich, F. Free Boundary Conditions at Austenite-Martensite Interfaces. Phys. Rev. Lett. 1995, 74, 746-749. [CrossRef] [PubMed]

4. Sittner, P.; Liu, Y.; Novak, V.J. On the origin of Luders-like deformation of NiTi shape memory alloys. J. Mech. Phys. Solids 2005, 53, 1719-1746. [CrossRef]

5. Sun, Q.P.; Li, Z.Q. Phase transformation in superelastic NiTi polycrystalline micro-tubes under tension and torsion-from localization to homogeneous deformation. Int. J. Solids. Struct. 2002, 39, 3797-3809. [CrossRef]

6. Li, Z.Q.; Sun, Q.P. The initiation and growth of macroscopic martensite band in nano-grained NiTi microtube under tension. Int. J. Plast. 2002, 18, 1481-1498. [CrossRef]

7. Yin, H.; Yan, Y.; Huo, Y.; Sun, Q. Rate dependent damping of single crystal CuAlNi shape memory alloy. Mater. Lett. 2013, 109, 287-290. [CrossRef]

8. He, Y.J.; Sun, Q.P. Rate-dependent domain spacing in a stretched NiTi strip. Int. J. Solids. Struct. 2010, 47, 2775-2783. [CrossRef]

9. He, Y.J.; Sun, Q.P. On non-monotonic rate dependence of stress hysteresis of superelastic shape memory alloy bars. Int. J. Solids. Struct. 2011, 48, 1688-1695. [CrossRef]

10. Zhang, X.H.; Feng, P.; He, Y.J.; Yu, T.X.; Sun, Q.P. Experimental study on rate dependence of macroscopic domain and stress hysteresis in NiTi shape memory alloy strips. Int. J. Mech. Sci. 2010, 52, 1660-1670. [CrossRef]

11. Morin, C.; Moumi, Z.; Zaki, W. Thermomechanical coupling in shape memory alloys under cyclic loadings: Experimental analysis and constitutive modeling. Int. J. Plast. 2011, 27, 1959-1980. [CrossRef]

12. Leo, P.H.; Shield, T.W.; Bruno, O.P. Transient heat transfer effects on the pseudoelastic behavior of shape-memory wires. Acta Metall. Materialia 1993, 41, 2477-2485. [CrossRef]

13. Nemat-Nasser, S.; Choi, J.Y.; Guo, W.G.; Isaacs, J.B. Very high strain-rate response of a NiTi shape-memory alloy. Mech. Mater. 2005, 37, 287-298. [CrossRef]

14. Chen, W.; Song, B. Temperature dependence of a NiTi shape memory alloy's superelastic behavior at a high strain rate. J. Mech. Mater. Struct. 2006, 1, 339-356. [CrossRef] 
15. Zurbitu, J.; Castillo, G.; Urrutibeascoa, I.; Aurrekoetxea, J. Low-energy tensile-impact behavior of superelastic NiTi shape memory alloy wires. Mech. Mater. 2009, 41, 1050-1058. [CrossRef]

16. Chen, W.W.; Song, B. Split Hopkinson (Kolsky) Bar: Design, Testing and Applications; Springer Science \&Business Media: Berlin/Heidelberg, Germany, 2010.

17. Shen, L.; Liu, Y.; Shan, J. Experimental study on temperature evolutionof pseudoelasticity TiNi alloys during shock-inducedphase transformation. Arch. Mech. 2018, 70, 191-205.

18. Liu, Y.G.; Shen, L.Y.; Shan, J.F.; Hui, M.M. Experimental study on temperature evolution and strain rate effect on phase transformation of TiNi shape memory alloy under shock loading. Int. J. Mech. Sci. 2019, 156, 342-354. [CrossRef]

19. Guo, Y.Z.; Ruan, Q.C.; Zhu, S.X.; Wei, Q.; Chen, H.; Lu, J.; Hu, B.; Wu, X.; Li, Y.; Fang, D. Temperature Rise Associated with Adiabatic Shear Band: Causality Clarified. Phys. Rev. Lett. 2019, 122, 015503. [CrossRef] [PubMed]

20. Pieczyska, E.A.; Gadaj, S.P.; Nowacki, W.K.; Tobushi, H. Phase-Transformation Fronts Evolution for Stressand Strain-Controlled Tension Tests in TiNi Shape Memory Alloy. Exp. Mech. 2006, 46, 531-542. [CrossRef]

21. Shaw, J.A.; Kyriakides, S. Initiation and propagation of localized deformation in elasto-plastic strips under uniaxial tension. Int. J. Plast. 1998, 13, 837-871. [CrossRef]

22. Pieczyska, E.A.; Tobushi, H.; Kulasiński, K. Development of transformation bands in TiNi SMA for various stress and strain rates studied by a fast and sensitive infrared camera. Smart Mater. Struct. 2013, 22, 035007-1-8. [CrossRef]

(C) 2020 by the authors. Licensee MDPI, Basel, Switzerland. This article is an open access article distributed under the terms and conditions of the Creative Commons Attribution (CC BY) license (http://creativecommons.org/licenses/by/4.0/). 